\title{
EMPLOYING THE AESTHETIC VALUES OF HERITAGE DESIGNS IN KINGDOM OF SAUDI ARABIA TO PRODUCE WOMEN VEST
}

\author{
Zainab Muhammad Munir Abdul-Gawad AL-SEBAEI*
}

Al-Qunfudhah University College, Umm Al-Qura University, KSA

\begin{abstract}
The research aims to study the possibility of presenting clothing design visions derived from the traditional costumes of the Kingdom of Saudi Arabia to produce a female bib, in order to preserve the heritage with its aesthetic and national values. The use of embroidery stitches recognized in traditional costumes to facilitate the production of the pieces industrially, then these designs were implemented within the projects of the clothing technology course. From several axes, the most important of which is the extent to which the piece expresses the source of the quotation, the aesthetic value of the piece, and its suitability for the modern era. The research followed a descriptive approach to solicit the opinions of specialists, producers and consumers on the proposed designs with application through the implementation of the designs.

Keywords

Fashion, Heritage, The southern region of the Kingdom of Saudi Arabia, Fashion design.
\end{abstract}

\section{Introduction}

The civilization of nations and peoples is not only measured by what they have in terms of economic and scientific development only, but also by what there is in it of a rich heritage and history, and the ability of its children to preserve and update this legacy. Today's heritage is one of the most prominent tourist attractions.

As a result of the expansion of the Kingdom of Saudi Arabia, its cultural and civilizational heritage has diversified, and it is divided into regions and each region has its own heritage, but in all regions of its different and diversity, the traditional dress of women in the Kingdom was represented in the robe, which they call the word (Daraa).

These traditional costumes have an indispensable role in affirming the customs, customs and traditions, as they are like a work of art and folklore that express the thought and culture of a people.

The traditional cloak differs from the traditional abaya in the Kingdom today, in the diversity of the colors of the traditional cloak and its decoration, which was executed with pure silver thread embroidery, and covered large parts of the cloak.

Among the studies related to the field of research are the study (Razan Abd Al-Qahtani - 2012) that carried out contemporary artworks derived from the Asiri folk costume, and the study of (Dr. Abeer Ibrahim Abd Al-Hamid Ibrahim - 2012) that dealt with the worker's men's fabrics of the southern region of Saudi Arabia. In designing the mechanics and the possibility of

* Corresponding author: callcenter@uqu.edu.sa 
adapting this traditional material and benefiting from its aesthetic and artistic characteristics using three-dimensional technologies, and the study of (Noura bint Siddiq bin Ibrahim Mukrish - 2010), which created designs for women's fashion inspired by the marine nature of the Kingdom of Saudi Arabia.

Although all of these studies were partly related to the idea of the current research, they agreed in terms of the idea and its extracted results, which recommended research towards technical sources, approaches and various methods to open up the field of artistic insights from innovations in the field of fashion design.

The Saudi traditional costumes for the southern region are distinguished by their aesthetic values and artistic richness, but they have not received sufficient attention in terms of their aesthetic and functional value.

\section{Research Problem:}

1- What are the aesthetic and artistic characteristics of Saudi traditional costumes in the southern region?

2- What is the possibility of employing the building blocks of selections of Saudi traditional costumes in the southern region in a Harem bodice design?

3- Are there statistically significant differences between the proposed designs from the viewpoint of the research sample A- Specialists B- Consumers

4- What is the possibility of implementing the proposed designs in ready-made clothes factories from the viewpoint of the producers?

\section{Research objectives:}

1- Learn about the aesthetic and artistic characteristics of Saudi - traditional costumes in the southern region.

2- Taking advantage of these characteristics and employing them in a Harem bib design.

3- Getting acquainted with the opinions of specialists, producers and consumers on designs inspired by Saudi traditional costumes in the southern region.

4- Implementing the designs to ensure their suitability for application and implementation.

\section{Research importance:}

Attempting to link popular legacies with the dress of modern women to preserve the national identity, and the results of the research can contribute to the presentation of proposals for the designs of vests for contemporary women inspired by the heritage and bearing the character of originality and suitable for wearing in the morning period and received a turnout from consumers and producers, and the research deals with one of the branches of science related to the field of Fashion design and new design resources. 


\section{Research Methodology:}

This research followed a descriptive approach to its suitability to achieve the research objectives to seek the opinions of specialists, producers and consumers on the proposed designs with application through their implementation.

\section{Research Delimitations:}

The limits of the research were limited to analyzing and extracting aesthetics for the traditional Saudi outfits in the southern region, and employing them in designing and implementing 10 Harem bras designs. For the morning period.

\section{The research sample:}

It consisted of 40 items distributed as follows:

- (9) From the specialists, and they are meant by the faculty members in the clothing and weaving department, to get acquainted with their views on the designs inspired by Saudi traditional costumes in the southern region.

- (19) consumers, and they mean community members of young women between the ages of (17: 58), to find out the extent of their acceptance of the designs inspired by Saudi traditional costumes in the southern region.

- (10) of the producers, including the gentlemen, the producers of the Harem outerwear, especially the (Bra) product, to get acquainted with their views on the designs inspired by Saudi traditional costumes in the southern region and the possibility of their implementation and commercialization.

\section{Research Tools:}

- References containing descriptions and pictures of Saudi traditional clothes and ornaments.

- Photoshop program to draw designs with the materials used in their implementation.

- Questionnaire form for arbitrators.

- Questionnaire form for university students in Saudi Arabia, aged (18-24).

- Questionnaire form for clothing producers.

- Raw materials used in the designs executed from fabrics and costumes.

- SPSS program for analyzing the results

The Saudi women's dress has gone through many stages of development in terms of colors, fabric quality and materials used in embroidering on the cloth. This outfit differed according to the different regions of the Kingdom, as the Najd, Eastern and Northern regions were famous for their pickpocket dress and the Daraa (jalabiya), the Asir region was known for the Asiri dress, and the Hijaz region was famous for the customer and the princess with the round, and with the difference in the dress from one region to another, he maintained his dignity, decency 
and originality.

Jewelery is similar in most regions of the Kingdom, in the way they are worn, worn and the occasions on which they are presented. They are usually known by their popular names in a particular area. By the people of other areas. Also, for geographical reasons, it carries, in addition to its well-known names across the Kingdom, with special local names. An example of this is the earrings that are attached to the call to prayer, which is a name known before Islam. Nevertheless, the common name for earrings in the eastern region is Taraji or Taraki, and in Najd and some areas of the Hijaz, khmakhm and Kharous. In Asir and the rest of the southwest of the Kingdom, it is known as Al-Khursan.

The jewelery prevalent in the Kingdom can be classified according to their different types, shapes, manner of wearing and characteristics as follows: On the circumference of the head, bells and shawls hang from its lower end, and are tied behind the head with a rope.

It has several types and names according to what it appears on it from the decorations, including a crown ring, a mother-of-three crowns gang, a sun gang, and a dog gang. It is one of the important head jewelry, including the cap, the neck, the crescent, the ring, the skeletons, the grilles, the meanings, the anemones, the sun and the harrows.

\section{As for hair ornaments, the most popular of them is limited to four types, which are:}

1- The khadid, which is a hair ornament that is worn on both sides of the head over the khimar and is known as its samadah or its temples, and it may be small and resembling a concrete, or slightly larger. Its decoration and components are similar to the medium-sized reed of ear ornaments.

2- Al-marsen and its types include Morsen Abu syringes, Mersen Abu three syringes, and Mersen Abu four syringes

3- Hama (crown), which is worn over the head

4- Iqal, which is worn over the head, and there are weaves hanging from it over it, with rows of silver inlaid, some of them riyals or half-riyals of silver.

\section{Terminology:}

\section{- Costumes:}

Fashion in the Arabic language is the plural of costume. It means the dress or the robe, meaning that everything that a person wears or covers his body from head to feet is considered uniform.

\section{- Heritage:}

It is what is transmitted from one generation to another from the customs, traditions, sciences, literature, arts and the like. Saleh Zayadneh

The southern region of Saudi Arabia 
The southern region or the south are all names given to the southwestern regions in the Kingdom of Saudi Arabia, which are Asir, Jizan, Najran, and Al-Baha.

https://ar.wikipedia.org/wiki.

\section{- Fashion Design:}

It is a plan or group of plans for the foundations and elements of the design and organizing the aesthetic relationships between them to produce an innovative costume (Benton: 1996-298). In the research, it is intended to provide proposed artistic visions for a (Haremy bodice) product that depends in its lines, colors, and space on the structural and decorative design and the technical features of the traditional costumes of the Kingdom of Saudi Arabia.

\section{Results and answers to questions:}

The results showed that the research objectives were achieved in employing the aesthetic and artistic characteristics of the traditional costumes in the Kingdom of Saudi Arabia in the proposed designs. And girls from the age of (12 to 48) who produce clothes, and accordingly the following hypotheses were drawn up and verified as follows:

The first hypothesis: "There are statistically significant differences between the designs implemented to employ the aesthetic and technical characteristics of the heritage designs of the mantle in the Kingdom of Saudi Arabia according to the opinions of specialists in achieving three aspects which are (innovation - aesthetics of design elements - aesthetics of the design foundations).

The second hypothesis: "There are statistically significant differences between the designs implemented to employ the aesthetic and technical characteristics of the traditional costumes in the Kingdom of Saudi Arabia, according to the opinions of girls from the age of $(19: 48)$ in achieving the two dimensions (aesthetic - functional), and thus the second assumption of the research is fulfilled.

The third hypothesis : The proposed designs can be implemented and commercially marketed.

- In light of the results of the research, several recommendations were made, including: Paying attention to the study of heritage because of its great importance as a source of modernity, as it is an inexhaustible aid for the artist in the modern era and in all ages, and conducting more studies linking the art of fashion design and various popular legacies.

The first question states, "What are the aesthetic and artistic characteristics of Saudi traditional costumes in the southern region?"

The researcher found that one of the technical features of these costumes is the presence of the black color of the cloak (daraa), and then it is distributed in the colors of red, yellow, and green decorations, in addition to silver and gold. 
As for the shape, it was always simple, represented by a cloak that is set on the body at the top and then begins to widen from the middle to the bottom until the end of the garment.

As for the decoration lines, they are embroideries consisting of parallel lines convergingly, these lines have a direction that is horizontal and then vertical, so that the shape of successive rectangles from the outside to the inside, these lines vary in their shapes and colors, and on the edge of the sleeves the horizontal embroidery lines are parallel in various shapes and colors. Even the cloth, which is known as the workbook, which is men's clothing in the southern region of the Kingdom of Saudi Arabia, and wears a veil, usually decorated with ornate threads on the edges, and is striped in green, red, orange, black and silver colors and is fed with metallic strings. It is usually worn on social occasions.

We see the strings hanging in the form of fringes in the headdresses known as the Taraqa alMashhala, which is a veil decorated with colored silk strings and has fringes on both sides with a silk thread called meshala.

As for jewelry, they are made of gold, silver and stones of different colors, and the jewelry was also characterized by the presence of gold or silver coins.

Despite the simplicity of the technical features of these outfits, they give inspiration for designs that are simple, yet elegant, and this meaning was confirmed by the international fashion designer Chanel, that elegance is in simplicity.

Its elegance is due to the availability of a number of design foundations in it, such as the unity represented in adopting the black color as the basis for the color of the pattern and adopting the embroidery style in its decoration, the compatibility between the colors used in the embroidery and the diversity that we see in the different shapes of lines in the embroidery, and the symmetrical balance where the similar elements are distributed visually on an axis One, and the rhythm, where the embroidery lines are repeated in the chest area and on the edge of the sleeves with a variation in the distribution of the lines in each of them.

\section{References:}

1- Elham Bint Sadaka Bin Sulaiman Jan - Culture and traditional folk arts in the Kingdom of Saudi Arabia and its role for societal development - The Third International Conference: Creativity, Innovation and Development in Architecture, Heritage, Arts and Literature "Future visions in the civilizations and cultures of the Arab world 3- 20 April 2018

2- Rehab Muhammad Ali Ismail - Safa Muhammad Jamal Ibrahim, miniatures as a source of inspiration to enrich the functional and aesthetic values of children's clothing Alexandria Journal of Agricultural Research Issue 60 No. 12015.

3- Shahraban Jaber Abdel Ghaffar - Using Egyptian Heritage to produce decorative and clothing designs for older women - Publisher Helwan University, College of Education, Volume 51 - Fourth Issue - October 2009 
4- Sally Fawzi Muhammad Al-Waraki - Revolution of January 57 as a source of inspiration in designing outfits to infuse the spirit of patriotism and belonging among young people, Faculty of Quality Education in Mansoura, Annual Conference (Sixth Arab-Third International) April 19-41, 2011

5- Siham Zaki Abdi Musa, wealthy Sayed Ahmed Nassr, and the son of Shaaban Mustafa Ramadan - an innovative vision of the Safavid era decorations in Iran and their use to enrich the embroidered pendants - The Journal of Qualitative Education Research - Mansoura University - Volume 12 - 01/02/2008

6- Mr. Ali Zallat - Mansoura University - Faculty of Specific Education Prof. Dr. / Ali Mr. Zalat, Prof. Dr. Saad Al-Sayed Al-Abed, Najwa Kamel Al-Bousily- Benefiting from the integration of some elements of the Egyptian and Saudi folklore to enrich the decorative design of the Harami outerwear. .

7- Fatima Ahmad Al-Shafei - Quoting from the elements of the natural environment for the design and implementation of some veiled women's wear - Master's thesis of the Faculty of Home Economics, Menoufia University - 2011

8- A video menu explaining the method of conducting the statistics on the SPSS program

9- Suleiman's Kifaya - Sahar Ali Zaghloul - Basics of Fashion Design for Women 2009 - The World of Books

10- Hind Baghfar - Brides and Costumes of the Kingdom - Al Shaer Group - 2018

11- Hind Baghfar - Al-Halli Al-Shaabi in the Kingdom of Saudi Arabia - Refaat Printing Press - 2014.

12- Bouvier, G. (2018) .Clothing and meaning making: a multimodal approach to women's abayas.visual communication.Vol: 17 Iss: 2, pp. 187-207.

13- https://www.youtube.com/playlist?list=PL6h6i8XxotKmu_5let2Xci_WghL Fp0stA

14- Tahani Nasser Alajaji College of Arts and Design, - Abaya and its Aesthetic Fashion Role in Saudi ArabiaPrincess Nourah bint Abdulrahman University, Saudi Arabia

Received: February 15, 2018

Accepted: April 20, 2018 